\title{
Research and Practice of Five-axis Technical Talent Training Based on the Fusion of Industry and Education
}

\author{
Yuhong Song \\ Xi'an Aeronautical Polytechnic Institute, Shaanxi, China, 710089
}

Keywords: The fusion of industry and education; Five-axis technical talent; Research and practice

Abstract: As a key development and talent training fields of technical colleges, Five-axis technical talents are more and more important for the industry. The fusion of industry and education is an important way for technical colleges to realize their own transformation and upgrading, as well as an inevitable requirement of higher education in China. This paper introduces the basis of the curriculum system, and studies the differences between Chinese and German numerical control technician training concepts. In addition, it analysis the necessity of "double-class parallel" for talent cultivation, and sorted out a systematic path.

\section{Introduction}

The five-axis CNC machine is a high-precision machine tool for machining complex surfaces or polyhedral parts. However, five-axis machining equipment is expensive and the toolpath prediction is very complicated. Therefore, many colleges and universities can only carry out training through computer programming, and rarely carry out practical processing training on machine tools. Five-axis processing enterprises often suffer from lack of technicians and low equipment utilization. The lack of demonstration courses for the training of five-axis processing talents cannot meet the talent needs of enterprises. In recent years, some companies have accumulated a certain amount of experience in the five-axis processing training courses and personnel training process. In recent years, some enterprises have accumulated certain experience in the five-axis processing training course and personnel training process by participating in the five-axis processing training class experience and the national numerical control competition practice. However, this experience has not yet formed a complete system, and there are still many shortcomings in the training of five-axis talents.

\section{The difference of China and Germany CNC technician training concept}

The training focus of general CNC technicians (3-axes, for example) mainly has the following differences, as shown in Figure 1. The mathematical foundation of German students is generally worse than that of Chinese students. The training of ordinary CNC technicians is mainly based on the following aspects: learning interest and quality, cost awareness. The training of Chinese CNC technicians took a lot of time to memorize the programming code, while German children basically 
used dialogue programming techniques in the entry phase. Germany generally saves more time to strengthen process and inspection techniques, thereby increasing quality and cost awareness.

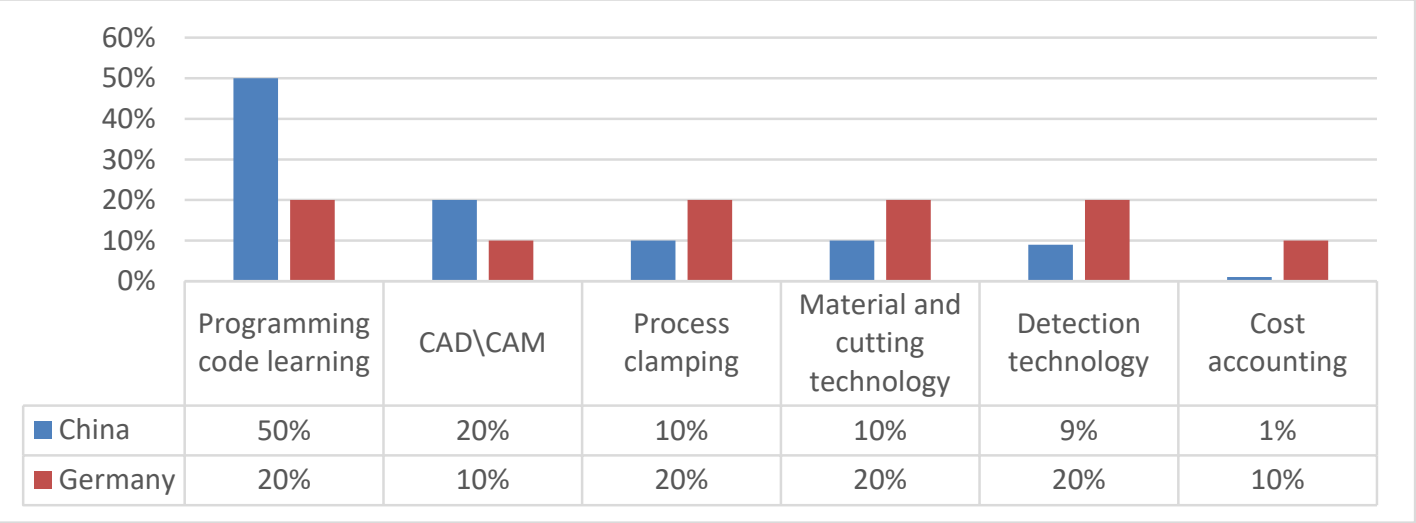

Figure 1. Different training focus of 3-axis CNC technician

The training focus of the senior numerical control technician (5-axis, for example) mainly has the following differences, as shown in Figure 2. Germany's advanced CNC technician training is based on the "3+2" five-axis basic spatial thinking ability. An in the next step, they will strengthen project and cost awareness to help students understand the management philosophy of the company. On the other side, Chinese training focuses on computational programming techniques, and the concept of five-axis spatial transformation is still weak. Therefore, in the absence of machine tool modeling and case simulation, machine impact is likely to occur, which increased the cost of enterprises.

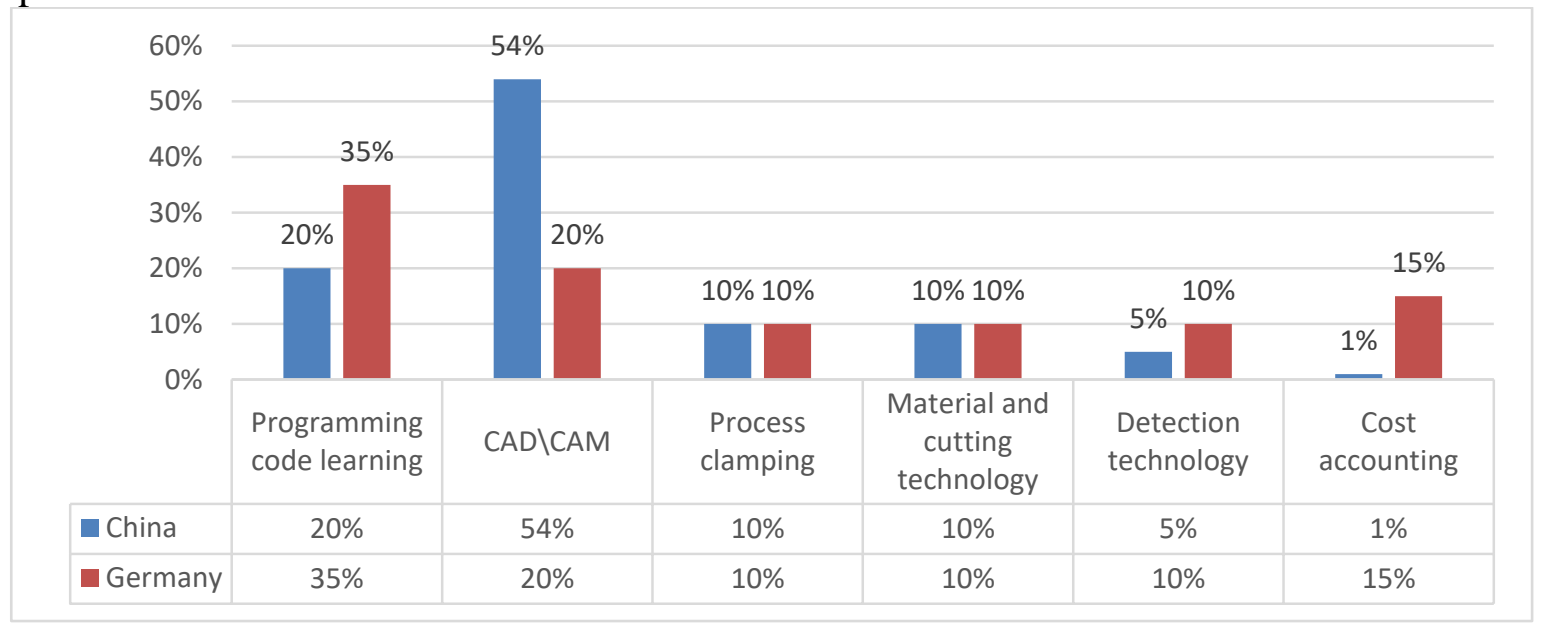

Figure 2. Different training focus of 5-axis CNC technician

\section{The talent training mode both on the fusion of industry and education}

\subsection{The characteristics of talent training mode}

The training of 5-axis CNC technician requires not only the basic hardware foundation, but also the information exchange between the school and the enterprise. In actual situation, the talent training model that combining production, study and research has the following three characteristics.

1) The school is responsible for the teaching of theoretical and practical courses.

2) Strengthen the exchange of information between schools and enterprises. 
3) The school updates the training course and assessment system in a timely manner based on feedback.

The purpose of the training model is not only to provide training for 5-axis CNC technology application engineers, but also to provide further training guidance for enterprise technicians.

\subsection{The frame diagram of talent training mode}

The frame diagram training mode can effectively improve the contradiction of the talents that the 5-axis trained in the school are not the kind of engineers that expected by the enterprise, and can effectively help students adapt to the management methods of the enterprise. The traditional training model lacks timely and effective information exchange, and it takes a long time for students to improve their skills after entering the enterprise. The frame diagram training mode can solve the problems in the internship through the course update and evaluation system update, which is an effective education model with low operating costs. Fig. 3 is a skeleton diagram of the cultivation mode.

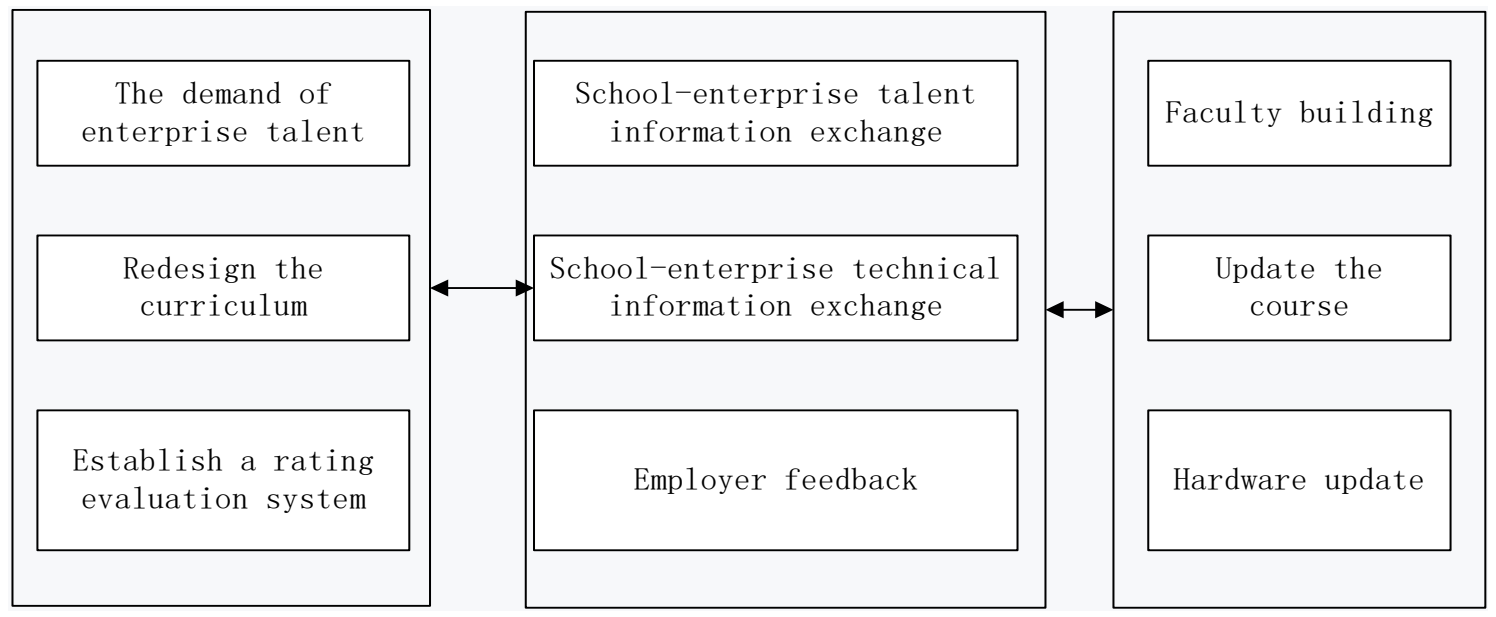

Figure. 3. The frame diagram of talent training mode

\section{The training path of 5-axis technical talents in the integration of industry and education}

\subsection{The framework process of school-enterprise cooperation}

The frame diagram training mode requires cooperation from different industries. For example, the public training base is the initiator, the enterprise provides practical positions and some equipment resources for teaching and training, and the software development organization provides advanced virtual simulation training software and virtual equipment, which can quickly Five-axis processing talents build an integrated teaching platform. The combination of platform structure and training course flow is shown in Figure 4.

The combination of platforms can give full play to the advantages of teaching and research in universities. According to the feedback from enterprises and universities, the typical teaching cases of enterprises and public training bases are integrated into the curriculum resource library. Through continuous optimization of the combination of training and curriculum structure, an integrated 5-axis processing training course system model is constructed. 


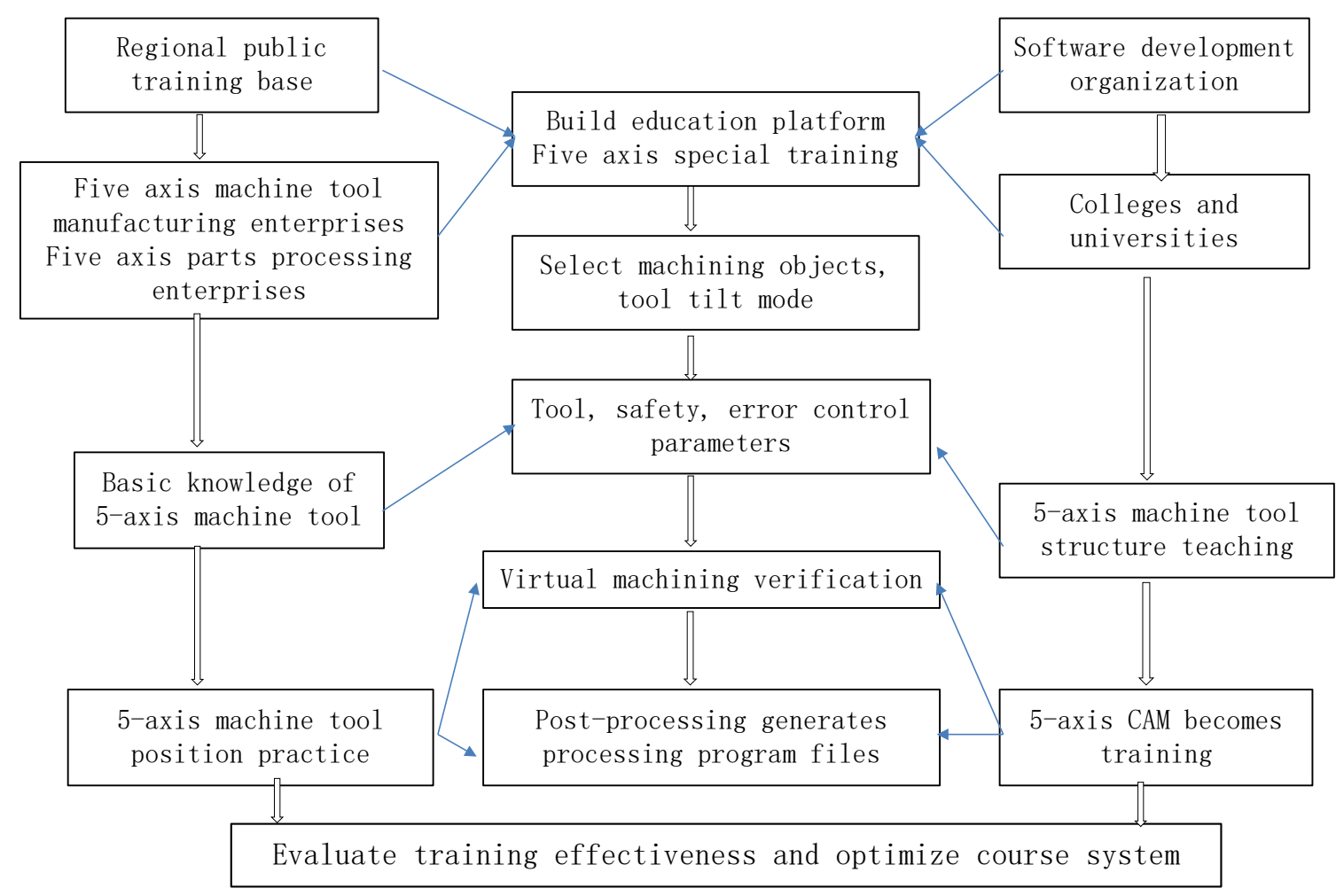

Figure 4. The framework process of school-enterprise cooperation

\subsection{Perfecting the integration system of industry and education}

\subsubsection{Building a cooperation mechanism}

To set up cooperation mechanisms, a cooperation committee should be set up with members from government, enterprises and schools, the members may be government teaching leaders, corporate technology elites, university professional leaders or key teachers. The cooperation committee coordinates the work of professional setting, talent development plan formulation, and coordination of school-enterprise relations, which will bring the integration of industry and education closer.

\subsubsection{Building a management mechanism}

Establishing a master plan and division of responsibilities will help to form the interdependence of industries, enterprises and universities. Through the combination of production, study and research, the teaching mode reform will be carried out in full accordance with the needs of production and management, so that the combination of production, study and research will be more dynamic. And through the establishment of specialized management institutions, it is conducive to the cultivation of five-axis technical talents under the joint management of universities and enterprises.

\subsubsection{Improving the feedback evaluation mechanism}

To Improving the feedback evaluation mechanism, it should improve the evaluation feedback mechanism, scientific evaluation methods, timely reflect problems, and through supervision, effectiveness evaluation and other means, comprehensive evaluation of the quality of five-axis personnel training and the integration of production, education and research, correct deviations in time, thus to contribute the training of 5-axis technical personnel. In addition, third-party evaluation 
can also improve the objectivity and effectiveness of the evaluation.

\section{Conclusion}

The content of the 5-axis CNC machining field is significantly more than just training and learning of motor skills. The basic theory of spatial geometry requires a lot of analysis, synthesis and transformation. Therefore, it is necessary to change the three-axis numerical control teaching method adopted in the past, and directly use the skill experience as the theme of the course. As well as combined with spatial geometry and multidimensional surface equations, share teaching resources with enterprises. Constructing a teaching model suitable for teachers' combination is the key focus of 5-axis CNC machining talent training. Universities, enterprises and software development enterprises should play a role in the process of training five-axis technical talents and continuously optimize the allocation of teaching resources, which helps to train more five-axis processing technicians.

\section{Acknowledgement}

Research and practice on the cultivation of skilled personnel under the 5-axes of production-education integration

\section{References}

[1] Lindberg Elisabeth, Persson Eva, Bondas Terese. The responsibility of someone else': a focus group study of collaboration between a university and a hospital regarding the integration of caring science in practice [J]. Scandinavian Journal of Caring Sciences,2012.

[2] Heinz Sunken Editorial. Knowledge Society/Knowledge Capitalism and Education [J]. Policy Futures in Education,2016(3).

[3] Rajani Naidoo. Cultural Perspectives on Higher Education [M].SpringerNetherlands, 2008. 